an important minority of patients in whom existing techniques frequently do not provide a clear diagnosis.

AVP is supported by the Conselho Nacional de Desenvolvimento Cientifico e Tecnologico, Brazil.

Requests for reprints should be addressed to Dr P J Ell, Department of Nuclear Medicine, The Middlesex Hospital Medical School, London W1N 8AA.

\section{References}

1 Carr, E A, et al, American Heart fournal, 1962, 64, 650.

2 Wackers, F J Th, et al, European fournal of Cardiology, 1976, 4, 273.

${ }^{3}$ British Medical fournal, 1978, 2, 717.

4 Parkey, R W, et al, Seminars in Nuclear Medicine, 1977, 7, 15.

5 Ennis, J T, Walsh, M J, and Mahon, J M, British Medical fournal, 1975, 3, 517 .
6 Lancet, 1978, 2, 299

7 Ahmad, M, et al, American fournal of Cardiology, 1977, 39, 50.

${ }^{8}$ Cowley, M K, et al, Circulation, 1977, 56, 192.

9 Berman, D S, et al, Circulation, 1975, 51, suppl No 2, p 53.

10 Prasquier, R, et al, Circulation, 1977, 55, 61.

11 Ahmad, M, Berman, D S, and Masion, D T, Americanfournal of Cardiology, 1978, 41, 349.

12 Joseph, S P, et al, British Heart fournal, 1978, 40, 234.

13 Ell, P J, et al, British Heart fournal, 1978, 40, 226.

14 McConahay, D R, et al, Circulation, 1970, 42, 245.

${ }^{15}$ Friedberg, C K, Diseases of the Heart, p 822. London, Saunders, 1966.

${ }^{16}$ Klein, M S, et al, Circulation, 1975, 51, suppl No 2, p 52.

17 Schelbert, H, et al, Circulation, 1975, 51, suppl No 2, p 70.

18 Klein, M S, American fournal of Cardiology, 1977, 39, 360.

19 Donsky, M S, British Heart fournal, 1976, 38, 257.

20 Willerson, J T, Circulation, 1976, 53, suppl No 1, p 128.

${ }^{21}$ Stern, S, et al, European fournal of Cardiology, 1977, 6, 167.

${ }^{22}$ Sobel, B E, and Shell, W E, Circulation, 1972, 45, 471.

${ }^{23}$ Coleman, R E, American fournal of Cardiology, 1976, 37, 732.

\title{
Successful treatment of exophthalmos and pretibial myxoedema with plasmapheresis
}

\author{
P DANDONA, N J MARSHALL, S P BIDEY, A NATHAN, C W H HAVARD
}

British Medical fournal, 1979, 1, 374-376

\section{Summary and conclusions}

A patient with Graves's disease with acute progressive exophthalmos and pretibial myxoedema was treated twice with plasmapheresis. Two weeks after the first treatment the symptoms recurred, but 20 weeks after the second treatment the exophthalmos was much improved and the pretibial myxoedema had disappeared. Analysis of sequential serum IgG concentrations and the thyroid-stimulating immunoglobulin index suggested that the two conditions were caused by specific IgGs.

The results suggest that plasmapheresis has a useful place in the treatment of acute and rapidly progressive ophthalmopathy and pretibial myxoedema in patients with Graves's disease.

\section{Introduction}

Graves's disease is characterised by abnormal immunoglobulin G's (IgG) in the plasma. Some of these displace thyrotrophin (TSH) bound to the thyroid follicular cell membran $\mathrm{e}^{1-5}$ and are known as thyroid-stimulating immunoglobulins (TSI). Others have biological effects on orbital tissues, ${ }^{6-11}$ are specific to sera from patients with exophthalmos, and may have a role in the pathogenesis of the ophthalmic complications of Graves's disease.

\section{Royal Free Hospital, London NW3 2QG}

P DANDONA, MRCP, DPHIL, director of metabolic unit

A NATHAN, MRCP, registrar, departments of chemical pathology and endocrinology

C W H HAVARD, DM, FRCP, consultant physician and endocrinologist

Middlesex Hospital and Medical School, London W1

N J MARSHALL, PHD, lecturer

S P BIDEY, PHD, research fellow, department of nuclear medicine
Plasmapheresis is an effective treatment in Goodpasture's syndrome $\mathrm{e}^{12}$ and myasthenia gravis, ${ }^{13}{ }^{14}$ where specific circulating IgGs mediate the basic injury. Hence it seemed appropriate to use plasma exchange in a patient with Graves's disease with progressive exophthalmos and pretibial myxoedema. We report the response of this patient in terms of both the clinical remission observed and sequential changes in serum IgG concentrations and TSI index.

\section{Case report}

A 57-year-old Caucasian woman presented in August 1977 with abdominal pain, diarrhoea, anxiety, palpitation, dyspnoea, and ankle swelling. She had pronounced tremor, proximal myopathy, and a diffuse, firm enlargement of the thyroid with a bruit. There was lid-lag but no lid retraction and no exophthalmos. Four years before she had had a left-sided radical mastectomy for carcinoma. Three female cousins of her father had had thyroid disease, and her husband had had recurrent thyrotoxicosis. Both her serum thyroxine (T4) concentration and free thyroxine index (FTI) were raised (T4 $199 \mathrm{nmol} / \mathrm{l}(15.5 \mathrm{\mu g} / 100 \mathrm{ml})$; FTI $\left.297^{\circ}{ }^{\circ}\right)$. She was given $30 \mathrm{mg}$ carbimazole daily, propranolol, and cyclopenthiazide-K but within three weeks developed an irritating exanthematous rash. The drugs were stopped, and in September she was treated with iodine - 131 $(10 \mathrm{mCi})$. Metoprolol and cyclopenthiazide-K were added.

In November periorbital oedema with minimal exophthalmos were noted. In December there was limitation of the upward movement of both eyes and pretibial myxoedema had developed. Serum T4 was still raised. Propylthiouracil $300 \mathrm{mg}$ daily was started. By January 1978 the pretibial myxoedema was more pronounced, and local Dermojet injections of triamcinolone (total dose $35 \mathrm{mg}$ ) into the lesions were administered. No noticeable improvement occurred. By March the pretibial myxoedema lesions had become hairy, pruritic, and greatly indurated. Onycholysis had appeared. Exophthalmos was severe (exophthalmometry: right $24 \mathrm{~mm}$, left $24 \mathrm{~mm}$ ). There was no upward movement of the eyes, and pronounced injection and chemosis of both conjunctivae were present. She was clinically and biochemically hypothyroid. Thyroxine $(0 \cdot 1 \mathrm{mg}$ daily) was added to the propylthiouracil treatment.

In view of the relentless progress of the exophthalmos and the risk of corneal injury she was admitted to hospital for plasmapheresis. She was given four sessions of plasma exchange on four successive days (plasmapheresis 1), carried out through a catheter in the femoral vein 
and with use of a Hemonetics cell separator. At each session 21 of plasma was exchanged for the same volume of isotonic saline and normal fresh-frozen plasma. A total loss of chemosis and conjunctival injection was observed 48 hours after starting plasmapheresis. By the end of four sessions periorbital oedema had disappeared and exophthalmos had diminished (exophthalmometry: right $21 \mathrm{~mm}$, left $23 \mathrm{~mm}$ ). Induration of the pretibial myxoedema lesions had also diminished.

Over the next two weeks chemosis and conjunctival injection returned, accompanied by a noticeable increase in the exophthalmos (exophthalmometry: right $24 \mathrm{~mm}$, left $24 \mathrm{~mm}$ ) and pretibial myxoedema. She was readmitted and plasmapheresis restarted (plasmapheresis 2): four sequential sessions with plasma exchange of $1.5 \mathrm{l}$ at each were carried out. She was also started on a combination of prednisolone $(80 \mathrm{mg} /$ day $)$ and azathioprine $(125 \mathrm{mg} /$ day) simultaneously. At the end of the four exchanges periorbital oedema, chemosis, and conjunctival injections had disappeared completely and the exophthalmos was much improved (exophthalmometry: right $21 \mathrm{~mm}$, left $23 \mathrm{~mm}$ ). The size and induration of the pretibial myxoedema lesions had greatly diminished. Twenty weeks later the improvement in exophthalmometry had been maintained. The pretibial myxoedema lesions had disappeared, and the normal contours of the legs were restored. The hair on the lesions had disappeared.

\section{Methods}

The sera were stored at $-20^{\circ} \mathrm{C}$ and IgGs prepared in a single batch by ammonium sulphate precipitation. ${ }^{1}$ Protein concentrations were estimated by absorption at $280 \mathrm{~nm}\left(\mathrm{E}_{1 \mathrm{~cm}}^{1 \%}=14\right.$ for human $\left.\mathrm{IgG}\right)$ and reported as the mean of triplicate determinations $\pm S E$ of mean. TSI indices were determined by the method of Mukhtar et al ${ }^{5}$ with TSH iodinated by the solid-phase lactoperoxidase method. ${ }^{15}$ The indices reported are the means of triplicate determinations $\pm S E$ of mean.

\section{Results}

During the first four days of plasma exchange (plasmapheresis 1 ) the serum IgG concentration changed little: the highest estimation (day 1) was $8.4 \pm 0.54 \mathrm{~g} / \mathrm{l}$, and the lowest (day 3) $6 \cdot 6 \pm 0.35 \mathrm{~g} / 1$ (no significant difference). These values were confirmed by immunodiffusion assay (Mancini) of the sera. On day 9, however, the serum IgG concentration had increased to $15 \cdot 1 \pm 0 \cdot 2 \mathrm{~g} / \mathrm{l}$ (fig 1 ). At the start of the second plasma exchange (plasmapheresis 2 ) the IgG concentration was estimated at $8 \cdot 3 \pm 0.5 \mathrm{~g} / \mathrm{l}$ and did not change significantly either during plasmapheresis or after immunosuppression. These findings were confirmed by determinations on a second-batch preparation (fig 1).

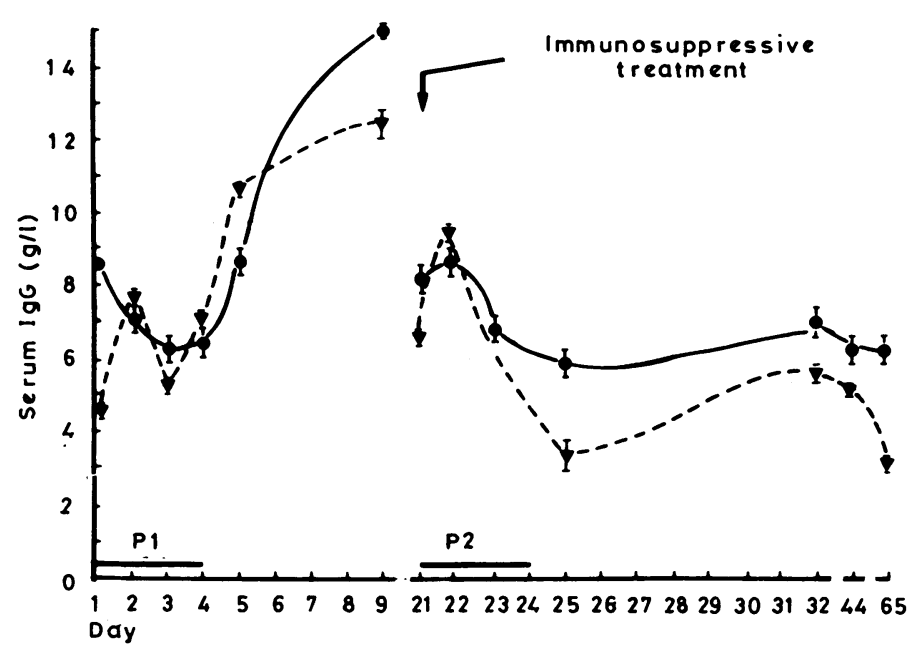

FIG 1-Changes in serum IgG concentration during and after plasmaphereses (P) 1 and 2 . Estimation from first-batch precipitation. $\nabla-$ Estimation from second-batch precipitation. Results expressed as mean of three determinations $\pm S E$ of mean.
Before plasmapheresis IgG from the patient's serum had potent TSI activity (TSI activity index $11 \cdot 4 \pm 82 \%$-that is, the test IgG displaced $88.6^{\circ}$ of TSH bound to thyroid membranes). The TSI index increased during the first period of plasmapheresis (day $4=33 \pm 5 \cdot 4$ ) but rapidly decreased on succeeding days (fig 2 ): day $5=6 \cdot 7 \pm 1 \cdot 6$; day 9 $=0$. Somewhat unexpectedly, the TSI index was increased on day 21 $(18 \pm 1 \cdot 9)$; but despite a transient decrease during plasmapheresis 2 on day 22 it was not observed to decrease to the same extent as it had after plasmapheresis 1 .

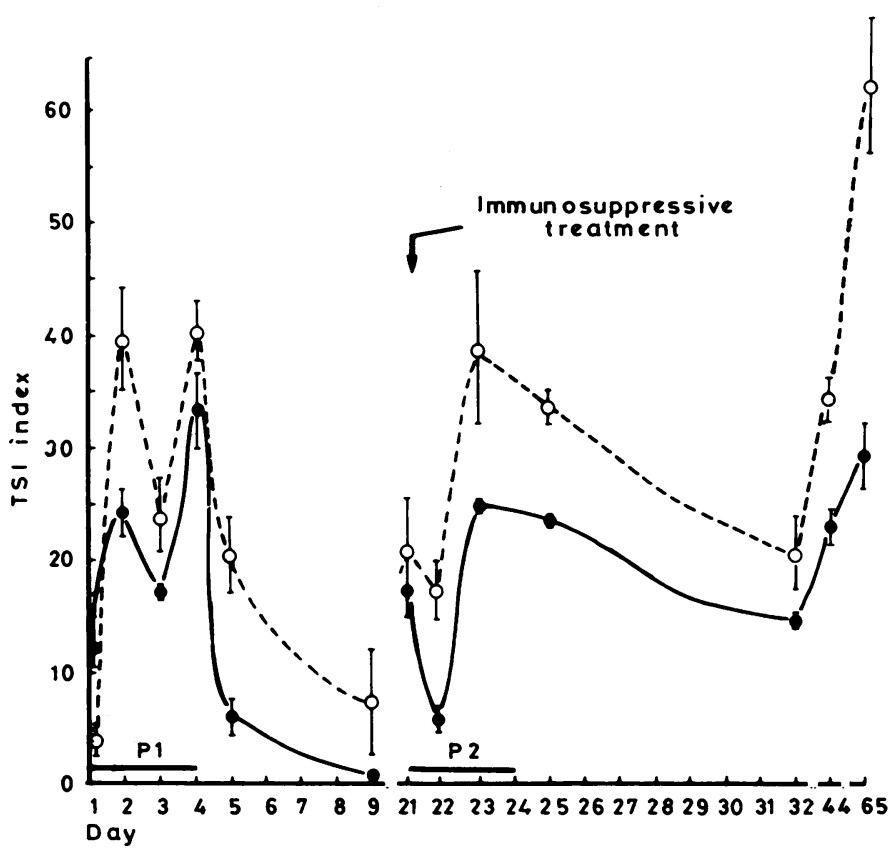

FIG 2-TSI indices during and after plasmaphereses (P) 1 and 2. Assay 1 ( ) : final IgG concentration in assay tube $13.3 \mathrm{~g} / 1$. Assay 2 $(0 \ldots-0)$ : final IgG concentration in assay tube $6.6 \mathrm{~g} / \mathrm{l}$. Aliquots of thyroid membranes and receptor purified ${ }^{125}$ I-thyrotrophin used for both assays were from same preparations. Results expressed as mean $(n=3$, assay $1 ; n=4$, assay 2) $\pm S E$ of mean

To minimise between-assay variation, the TSI indices shown in fig 2 were determined in one assay using a final concentration of $13.3 \mathrm{~g} \mathrm{IgG} / \mathrm{l}$. The observations were confirmed in a duplicate assay performed at a final IgG concentration of $6.6 \mathrm{~g} / \mathrm{l}$. With the lower concentration the changes in TSI indices were as described above but more pronounced. No soluble circulating immune complexes were found in the patient's serum using the $C_{1} q$ binding technique.

\section{Discussion}

The noticeable improvement in this patient's ophthalmopathy, in parallel with a rise in TSI index, after a series of plasma exchanges is consistent with the hypothesis that exophthalmos is caused by a circulating plasma factor, probably an IgG. The recurrence of exophthalmos within two weeks of the plasma exchange was associated with an increased serum IgG concentration and a decreased TSI index (day 9). This rebound of the IgG concentration parallels the observations after plasma exchange in animal models. ${ }^{16}{ }^{17}$ Although the TSI index is not a detection system for exophthalmic IgG, it served as a specific marker for a closely related IgG.

The immunosuppressive drugs prednisolone and azathioprine prevented the rapid recurrence of ophthalmopathy, an increase in the IgG concentration and a decrease in the TSI index occurring after the second course of plasmapheresis. This agrees with experience in myasthenia gravis and Goodpasture's syndrome. ${ }^{12} 14$ Corticosteroids suppress antibody synthesis, and azathioprine probably has a selective cytotoxic action on clones 
of lymphocytes selectively stimulated to proliferate after removal of IgGs from the circulation.

We did not expect the rapidity with which the pretibial myxoedema regressed in this patient. A plasma factor, possibly another IgG, may be responsible for the induction of pretibial myxoedema. Sera from patients with pretibial myxoedema enhance fibroblast growth and proliferation in vitro ${ }^{18}$ and accelerate the incorporation of labelled glucosaminoglycan precursors by fibroblasts in culture. ${ }^{19}$ The remarkably rapid resolution and the equally rapid reappearance of pretibial myxoedema in this patient indicate an extremely rapid turnover of glycosaminoglycans.

We suggest that plasmapheresis has a useful place in the treatment of the ophthalmopathy and pretibial myxoedema of Graves's disease. Both these complications have been extremely refractory to any form of treatment. The choice of patients must be made with care, as it is only in the acute and rapidly progressive disease that improvement is likely to occur.

We thank Professors Deborah Doniach and Ivan Roitt for their critical comments and help in the preparation of this paper, Professor A V Hoffbrand and Dr J Moorhead for the use of the Hemonetics cell separator, and Mrs M Elleman for secretarial help. NJM and SPB are grateful to the MRC for support during the course of this work.

\section{References}

${ }^{1}$ Smith, B R, et al, fournal of Endocrinology, 1977, 75, 401.

2 Doniach, D, and Marshall, N J, in Autoimmunity, ed N Talal. New York, Academic Press, 1977.

${ }^{3}$ Schleusener, H, et al, fournal of Endocrinological Investigation, 1978, 2, 155.

${ }^{4}$ Brown, R S, et al, Lancet, 1978, 1, 904.

${ }^{5}$ Mukhtar, E D, et al, Lancet, 1975, 1, 713

${ }^{6}$ Dandona, P, and El Kabir, D J, Clinical Science and Molecular Medicine, $1970,38,2 \mathrm{P}$.

' Winand, R J, Salmon, J, and Lambert, P, Wiener Medizinischen Akademie, 1971, p. 583.

${ }^{8}$ Singh, S P, and MacKenzie, J M, Metabolism, 1971, 20, 49F.

9 Winand, R J, and Kohn, L D, Proceedings of the National Academy of Sciences, 1972, 69, 1711 .

${ }^{10}$ Dandona, P, D Phil thesis, University of Oxford, 1974.

${ }^{11}$ Bolonkin, D, et al, fournal of Biological Chemistry, 1975, 250, 6516.

${ }^{12}$ Lockwood, C M, Rees, A J, and Pearson, T A, Lancet, 1975, 1, 711.

${ }^{13}$ Pinching, A J, Peters, D K, and Newson-Davis, J, Lancet, 1976, 2, 1373.

${ }^{14}$ Dau, P C, et al, New England fournal of Medicine, 1978, 297, 1134.

${ }^{15}$ Gill, D L, Marshall, N J, and Ekins, R P, Molecular and Cellular Endocrinology, 1978, 10, 89 .

${ }^{16}$ Bystryn, J C, Graf, M W, and Uhr, J W, fournal of Experimental Medicine, 1970, 132, 1279.

${ }^{17}$ Branda, R F, Moldow, C F, and McCullough, J J, Transfusion, 1975, 15, 570.

${ }^{18}$ Cheung, H S, et al, Clinical Research, 1977, 125, 147A.

${ }^{19} \mathrm{Jolliffe}, \mathrm{D}$, personal communication, 1978.

(Accepted 22 November 1978)

\title{
Treatment of irritable bowel syndrome with lorazepam, hyoscine butylbromide, and ispaghula husk
}

\author{
J A RITCHIE，S C TRUELOVE
}

British Medical fournal, 1979, 1, 376-378

be more effective, but it will be possible to determine this only by carrying out factorial therapeutic trials.

\section{Summary and conclusions}

A double-blind controlled therapeutic trial of factorial design was used to study the therapeutic effects of lorazepam, hyoscine butylbromide, and ispaghula husk in 12 randomised blocks of eight patients with the irritable bowel syndrome (IBS). Each of the three agents caused a sustained symptomatic improvement in some of the patients, although only with ispaghula was the difference between the real and dummy preparation statistically significant. When the eight possible combinations of treatment were analysed none of the 12 patients who received only dummy preparations of the three agents had maintained any improvement over the three months of the trial. Seven patients improved among the 12 who received potent preparations of all three agents, and between four and six patients improved in the groups receiving one or two of the potent preparations.

These therapeutic results, though far from perfect, show that the types of drug commonly used to treat IBS are of some value and may be additive in their effects. Similar combinations of other therapeutic agents may

\footnotetext{
Nuffield Department of Clinical Medicine, Radcliffe Infirmary, Oxford

J A RITCHIE, MA, DM, research fellow

S C TRUELOVE, MD, FRCP, consultant physician
}

\section{Introduction}

The irritable bowel syndrome (IBS) is a diagnostic label applied to patients who have various gastrointestinal symptoms that cannot be attributed to any recognised pathological process. These symptoms commonly include a disturbance of bowel function, with diarrhoea or constipation (or an alternation of the two), hypersecretion of colonic mucus, gastrointestinal flatulence, abdominal pain, and a general lack of subjective wellbeing expressed variously as tiredness, weakness, or depression. These symptoms may be either continuous or episodic. They appear to be related to excessive motor activity of some part of the gut, possibly through hyperreaction to parasympathetic and hormonal stimuli. Emotional tensions are apt to precipitate or exacerbate an episode of symptoms. It is a common condition and in a small proportion of those affected may give rise to severe disability. For many years medical treatment has been based on one or more of three types of therapeutic agent, with additional symptomatic control by aperients or antidiarrhoeal drugs as necessary. The three types of agent are: (1) an antispasmodic drug, usually either an anticholinergic or mebeverine (2) a sedative or tranquilliser, originally phenobarbitone but now commonly a benzodiazepine derivative; and (3) an inert faecal bulking agent, either pharmaceutical or obtained by way of increased dietary roughage.

The present study was undertaken to test the validity of clinical impressions that the basic treatment with antispasmodic, tranquilliser, and bulk-provider is of value in IBS. 